\section{Cureus}

\title{
Instillation Therapy for the Treatment of Necrotizing Fasciitis: A Case Study
}

\author{
Douglas F. Blazek ${ }^{1}$, Emily Lockridge ${ }^{1}$ \\ 1. Cornerstone Surgical Specialists, High Point Regional, UNC Healthcare
}

$\square$ Corresponding author: Emily Lockridge, emma_leigh1010@hotmail.com

Disclosures can be found in Additional Information at the end of the article

\section{Abstract}

A 57-year-old obese female with uncontrolled diabetes mellitus type I presented to the emergency department (ED) with the main complaint of worsening pain and redness in her right groin and inguinal regions. In the ED, a CT scan confirmed the likely presence of necrotizing fasciitis in the right groin and thigh. She was also found to be febrile and septic on admission. She was urgently taken to the OR for extensive debridement then admitted to the ICU for medical stabilization. She was subsequently taken back for serial debridements, and a negative pressure wound therapy with instillation (NPWTi-d) Veraflo device was placed once the wound was successfully debrided down to viable tissue. This is a case study on the wound progression of this patient.

Categories: Plastic Surgery, General Surgery, Infectious Disease

Keywords: necrotizing fasciitis, wound, instillation, veraflo, npwt, npwti-d, sepsis, diabetes, saline, surgical debridement

\section{Introduction}

A 57-year-old morbidly obese female with poorly controlled diabetes and sepsis and was found to have necrotizing fasciitis of the right groin and upper inner thigh. She was treated with multiple debridements in the operating room as well as by the ICU-Critical Care for her severe sepsis and diabetes management. She also had severe respiratory distress and required prolonged intubation and tracheostomy prior to discharging to the longterm acute care (LTAC) facility. After her wound had been debrided to viable tissue, a negative pressure wound therapy with instillation (NPWTi-d) Veraflo device was placed and continued for approximately one month until transitioned to negative pressure wound therapy (NPWT) device. Once medically stable, she was discharged to a LTAC facility with the NPWT in place.

Received 09/22/2016 Review began 09/27/2016 Review ended 12/01/2016 Published 12/07/2016

\section{(C) Copyright 2016}

Blazek et al. This is an open access article distributed under the terms of the Creative Commons Attribution License CC-BY 3.0., which permits unrestricted use, distribution, and reproduction in any medium, provided the original author and source are credited.

\section{Case Presentation}

A 57-year-old obese female presented to the emergency department with worsening pain and infection of the right inguinal region, right thigh, and lower abdominal wall. A CT scan confirmed the likely necrotizing fasciitis, and the patient was also found to have poorly controlled diabetes mellitus and sepsis on admission. She was admitted by the Critical Care team and emergently taken to the operating room for incision and drainage, with extensive debridement of her necrotizing fasciitis. The original wound size following this debridement was $60 \mathrm{~cm} \times 30 \mathrm{~cm} \times 15 \mathrm{~cm}$ down to the muscle. Her sepsis failed to resolve, and she was, therefore, taken back to the operating room 36 hours later for further debridement down to the muscle with a long segment of visible femoral artery and sciatic nerve exposed. She was taken back to the operating room again four days later for further debridement as she was too unstable during the previous procedures for prolonged anesthesia and blood loss. 


\section{Cureus}

Throughout the above-mentioned procedures, her wound was also thoroughly irrigated via pulsavac lavage. After the second debridement due to the severity of her wound, an orthopedic consult was obtained for an opinion on a hip disarticulation; they recommended proceeding with the current wound care and would proceed with disarticulation if she failed with the current therapy. Forty-eight hours following the 3rd OR debridement (Figure 1), an NPWTi-d Veraflo device was placed on the wound with normal saline instillation solution with the following settings: $325 \mathrm{ml}$ normal saline was instilled for a 10 minute soak every three and a half hours under $-125 \mathrm{mmHg}$ continuous pressure per the recommendations of the clinical panel [1-4] (Figure 2). Use of normal saline for instillation was chosen as studies have shown that it is as effective as other topical wound cleaning solutions [5-6]. Similar to the use in this patient, multiple clinical trials have shown that NPWTi-D versus NPWT achieves faster wound closure and better skin perfusion when used with -125 $\mathrm{mmHg}$ [7-9].

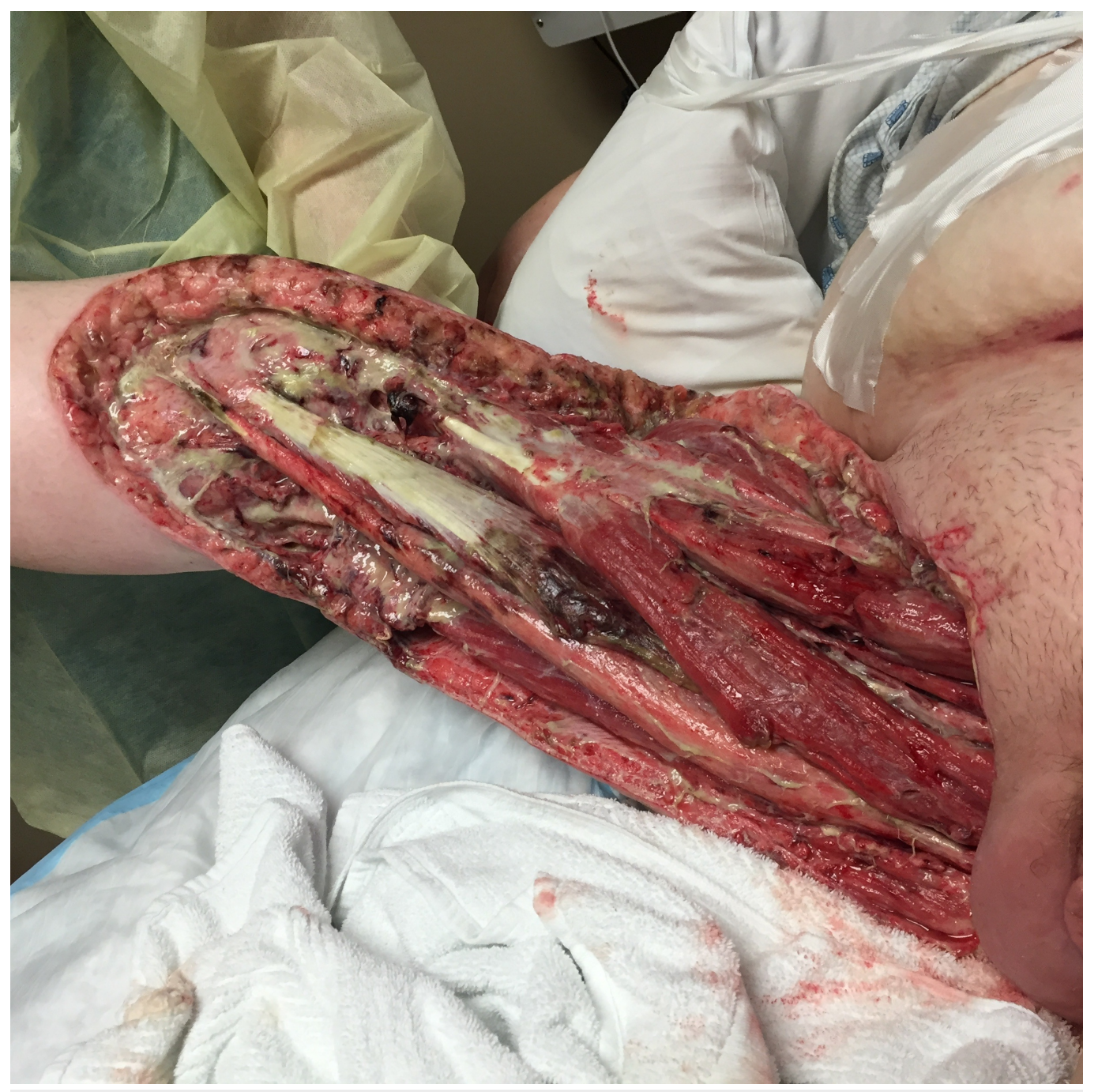

FIGURE 1: Initial Wound Following Mutliple OR Debridements, Prior to Placement of NPWTi-D Therapy 


\section{Cureus}

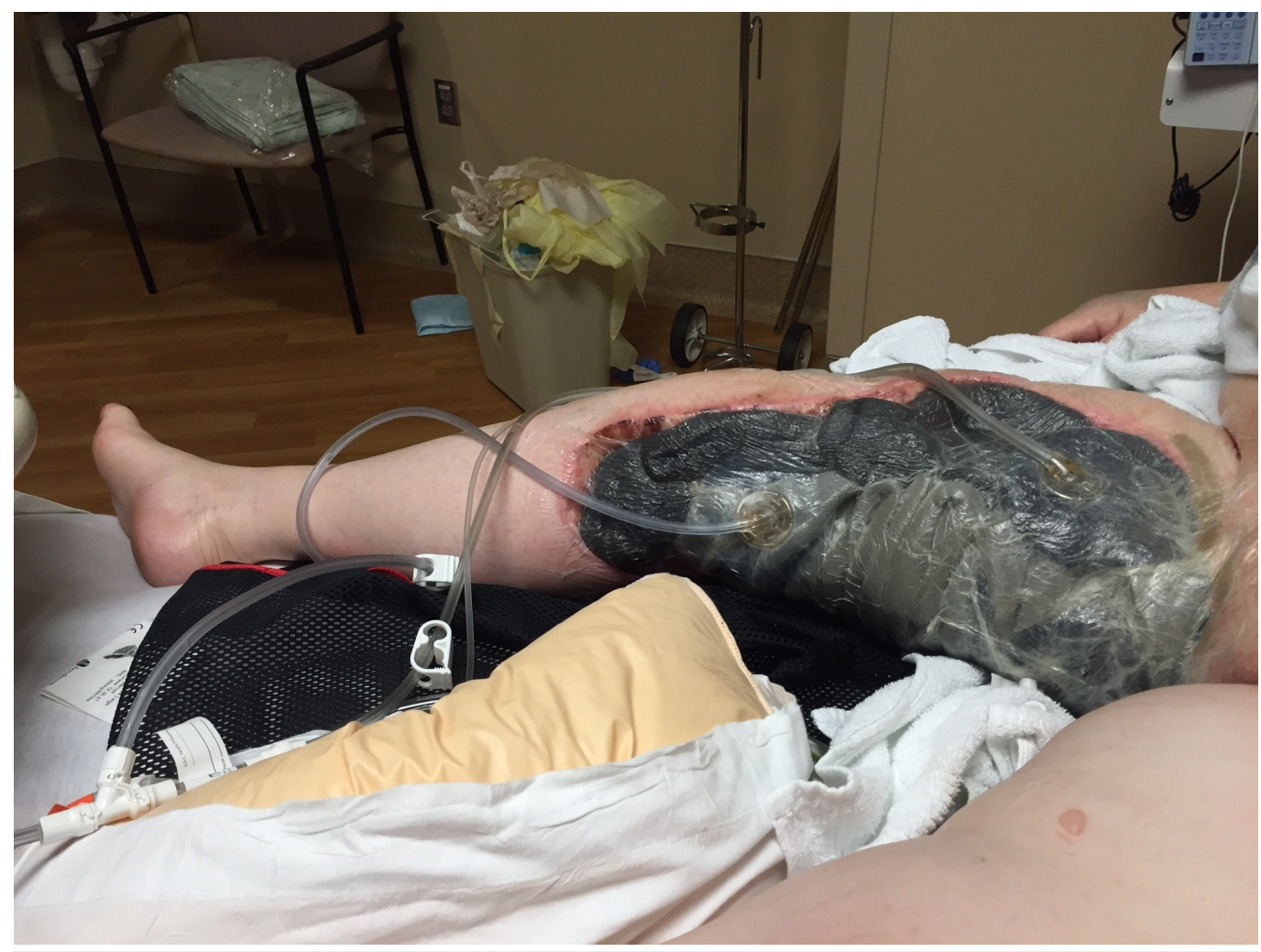

FIGURE 2: Demonstration of the Extensive Size of Wound Following the First Application of NPWTi-D

The dressings were changed on a 3-4 day schedule. After four days of treatment with the NPWTi-d Veraflo, the wound showed improvement with increased granulation tissue and viable skin edges, with granulation over the exposed artery and nerve (Figure 3). 


\section{Cureus}

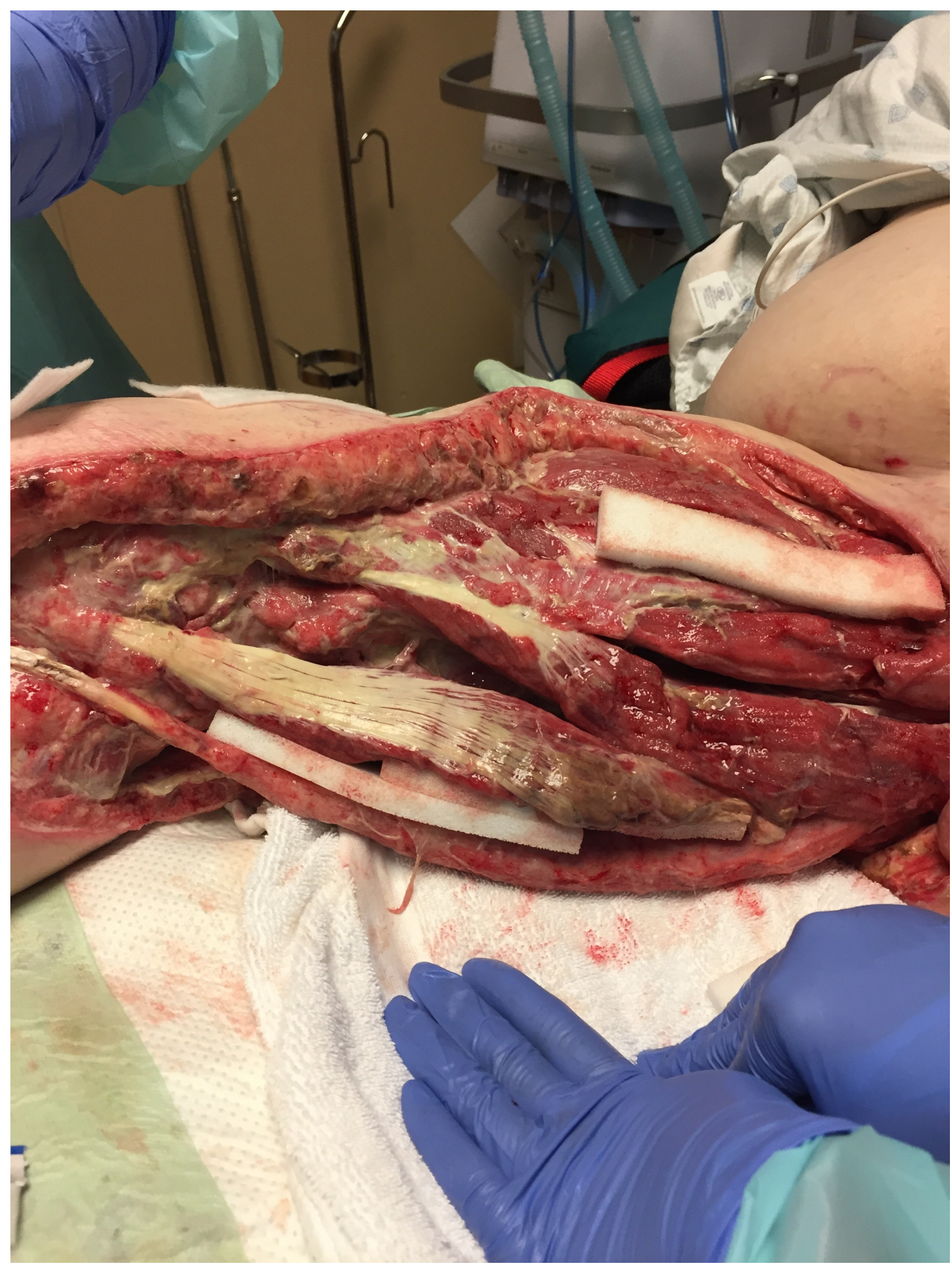

FIGURE 3: First NPWTi-d Dressing Change

White foam still in place which was protecting exposed vasculature and nerve structures.

The patient had a prolonged hospital course. Once she was off sedation and medically stable, due to the size and extent of her wound, she was taken back to the OR three days later for a dressing change, and the overall wound showed great improvement with increased granulation throughout (Figure 4). 


\section{Cureus}

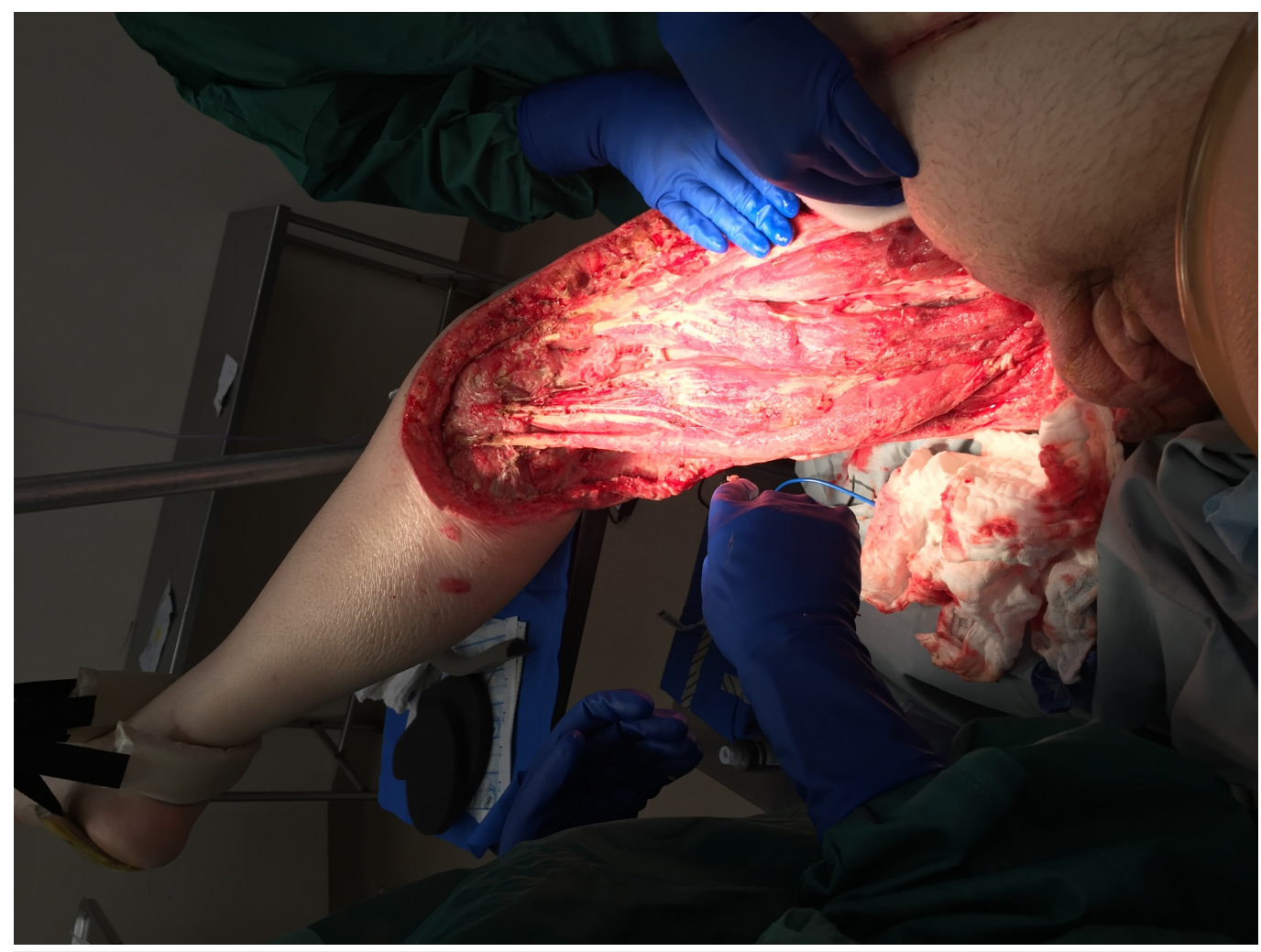

\section{FIGURE 4: Third Dressing Change Following NPWTi-D Therpay}

This shows increased granulation over exposed vasculature, nerves, and exposed muscles and tendons.

NPWTi-d Veraflo therapy was continued with one more subsequent dressing change seven days later and then returned to NPWT $-125 \mathrm{mmHg}$ until discharge from the hospital to the LTAC facility. NPWT was continued with dressing changes three times weekly at the outside LTAC facility as discussed for continued therapy for expedited granulation. The patient was then readmitted 20 days later for other medical complications; the wound was evaluated and exhibited almost complete granulation over all exposed muscle, vasculature, and nerve structures--almost superficial to surrounding peri-wound skin (Figure 5). 


\section{Cureus}

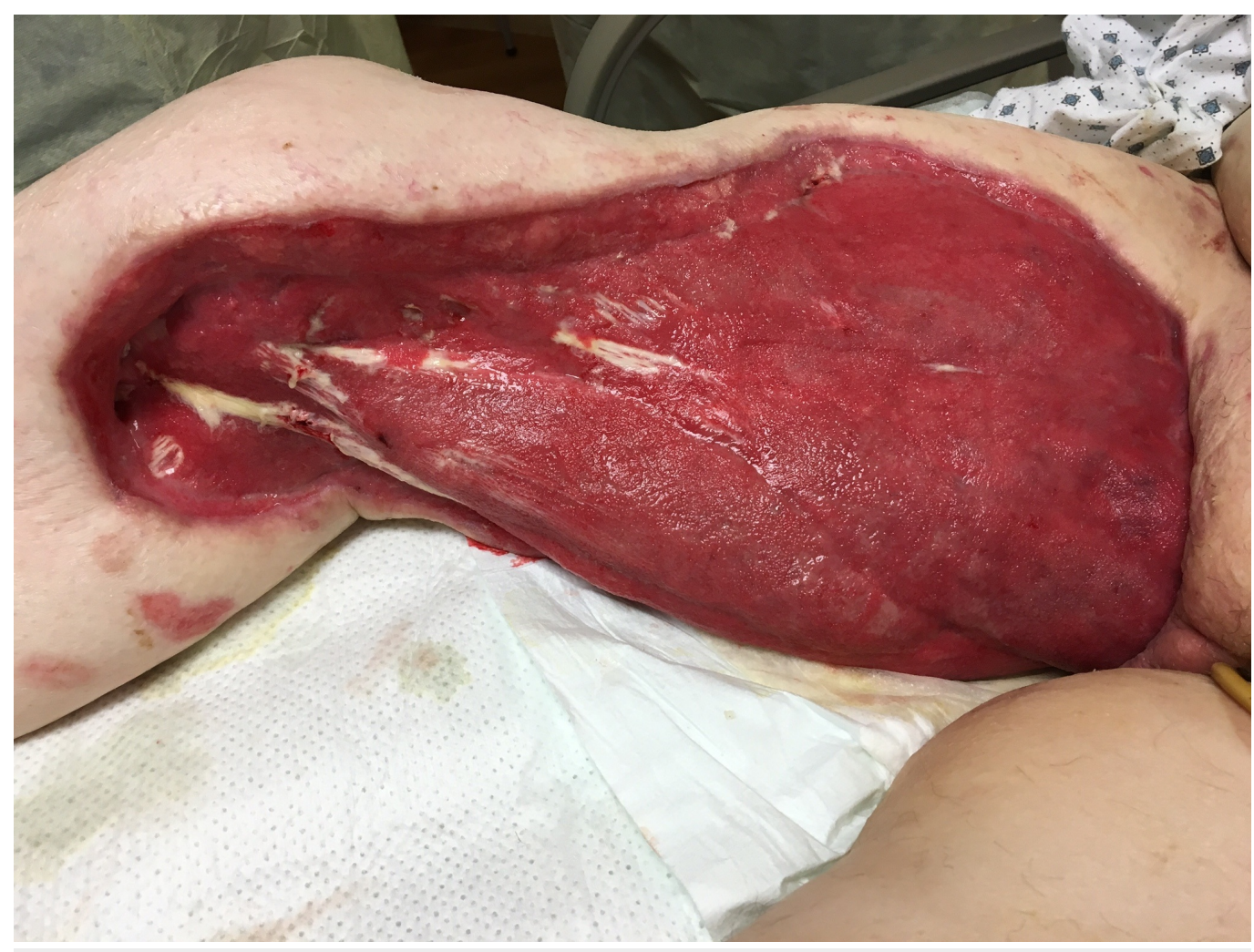

FIGURE 5: The Wound After the Patient Had Been Transitioned to NPWT, Approximately One Month Following the Initial Placement of NPWTi-D Therapy

She was once again discharged to the LTAC facility with NPWT. The patient was then readmitted about 30 days later for VRE pneumonia and expired from this, therefore complete closure of her wound was not able to be achieved. Informed consent was waived, and no reference to the patient's identity was made at any stage during data analysis or in the report.

\section{Discussion}

The following questions should be asked when considering NPWT versus NPWTi-d:

Was the VeraFlo therapy a critical component of this patient's limb salvage?

Did the VeraFlo therapy expedite healing for this patient?

Were the VeraFlo dressing changes easier to manage than standard-of-care dressings?

These are some of the considerations that were taken prior to developing the appropriate treatment plan for this patient. Overall, she had a great response with rapid granulation tissue growth following her NPWTi-d therapy. The authors strongly feel that she could have undergone a muscle flap/split thickness skin grafting to complete her wound closure if she had not unfortunately expired from her other multiple medical comorbidities.

\section{Conclusions}

VeraFlo played a critical role in the limb salvage as orthopedics was consulted for total hip 
disarticulation for this patient prior to initiation of VeraFlo therapy. Had she not responded so well to the VeraFlo therapy, the hip disarticulation would have ultimately been necessary to save her life. VeraFlo therapy was chosen after reviewing the cited articles, publications, and websites [1-10].

Healing was greatly expedited with the use of VeraFlo therapy in this case. A soft tissue deficit of this magnitude could potentially take years to granulate in and epithelialize. Instead, using VeraFlo, we saw rapid granulation and coverage of exposed nerves, vasculature, and tendons in just weeks.

The VeraFlo dressings were changed at the bed-side twice per week. Standard-of-care wound dressings for this type of wound are typically done twice daily. This saved significant nursing time and supply costs. VeraFlo therapy also decreased the number of times we needed to sedate the patient to undergo dressing changes. We were ultimately able to cut back on the number of operative debridements, which saved time and expense to the hospital.

\section{Additional Information}

\section{Disclosures}

Human subjects: Consent was obtained by all participants in this study. Conflicts of interest: In compliance with the ICMJE uniform disclosure form, all authors declare the following:

Payment/services info: All authors have declared that no financial support was received from any organization for the submitted work. Financial relationships: All authors have declared that they have no financial relationships at present or within the previous three years with any organizations that might have an interest in the submitted work. Other relationships: All authors have declared that there are no other relationships or activities that could appear to have influenced the submitted work.

\section{References}

1. V.A.C. Veraflo. (2016). Accessed: September 22, 2016: http://www.veraflo.com.

2. Acelity. (2016). Accessed: September 22, 2016: http://www.acelity.com.

3. KCI. (2016). Accessed: September 22, 2016: http://www.kci1.com.

4. McKanna M, Geraci J, Hall K, et al.: Clinical panel recommendations for use of negative pressure wound therapy with instillation. Ostomy Wound Management. 2016, 1-17. Accessed: September 22, 2016: http://www.o-wm.com/files/owm/Acelty_Supp_0416.pdf.

5. Kim P, Attinger CE, Oliver $\mathrm{N}$, et al.: Comparison of outcomes for normal saline and antiseptic solution for negative pressure wound therapy with instillation. Plast Reconstr Surg. 2015, 136:657e-664e. Accessed: September 22, 2016: 10.1097/PRS.0000000000001709

6. Brinkert D, Ali M, Naud M, Maire N, Trial C, Téot L: Negative pressure wound therapy with saline instillation: 131 patient case series. Int Wound J. 2013, 10 Suppl 1:56-60. 10.1111/iwj.12176

7. Timmers MS, Le Cessie S, Banwell P, Jukema GN: The effects of varying degrees of pressure delivered by negative-pressure wound therapy on skin perfusion. Ann Plast Surg. 2005, 55:665-671. 10.1097/01.sap.0000187182.90907.3d

8. Kim PJ, Attinger CE, Steinberg JS, et al.: The impact of negative-pressure wound therapy with instillation compared with standard negative-pressure wound therapy: a retrospective, historical, cohort, controlled study. Plast Reconstr Surg. 2014, 133:709-716. 10.1097/01.prs.0000438060.46290.7a

9. Gabriel A: Integrated negative pressure wound therapy system with volumetric automated fluid instillation in wounds at risk for compromised healing. International Wound Journal. 2012, 9 suppl 1:25-31. 10.1111/j.1742-481X.2012.01014.x

10. Sabiston Textbook of Surgery: The Biological Basis of Modern Surgical Practice, 18th Edition . Townsend CM Jr., Beauchamp RD, Evers BM, Mattox KL (ed): Elsevier Saunders , Philadelphia, PA; 2008. 1:213-216. 